Conservation Biology of Freshwater Turtles and Tortoises:

A Compilation Project of the IUCN/SSC Tortoise and Freshwater Turtle Specialist Group

A.G.J. Rhodin, P.C.H. Pritchard, P.P. van Dijk, R.A. Saumure, K.A. Buhlmann, and J.B. Iverson, Eds.

Chelonian Research Monographs (ISSN 1088-7105) No. 5, doi:10.3854/crm.5.010.intergularis.v1.2008

(C) 2008 by Chelonian Research Foundation • Published 20 June 2008

\title{
Pelusios castanoides intergularis Bour 1983 - Seychelles Yellow-Bellied Mud Turtle, Seychelles Chestnut-Bellied Terrapin
}

\author{
JUSTIN GERLACH ${ }^{1}$ \\ ${ }^{1} 133$ Cherry Hinton Road, Cambridge CB1 7BX, United Kingdom [jstgerlach@aol.com]
}

Summary. - The Seychelles subspecies of yellow-bellied mud turtle, Pelusios castanoides intergularis (Family Pelomedusidae), is restricted to six islands of the Seychelles group. Four breeding populations remain and the extant wild population was estimated at only 120 adults in 2005. Populations continue to decline due to ongoing marsh drainage and river canalization. Legal protection of wetland habitats is urgently required, and ongoing reintroductions to protected areas need to continue to secure the future of this species.

Distribution. - Seychelles. Found only in the granitic Seychelles on Mahé, Cerf, Silhouette, Praslin, La Digue, and Fregate islands.

Synonymy. - Pelusios castanoides intergularis Bour 1983.

STATUS. - IUCN 2007 Red List: Critically Endangered (CR A2c; B2ab(ii,iii)) (assessed 2003); CITES: Not Listed; Seychelles WAPR: Protected.

Taxonomy. - Animals of this subspecies from the Seychelles were first recorded as Sternothaerus castaneus (Duméril and Bibron 1835) and later confused with both Pelusios subniger and with $P$. seychellensis. Recognized as distinct and described as a Seychelles endemic subspecies by Bour (1983).

The nominate subspecies (P. c. castanoides) occurs in Africa and Madagascar (Bour 1983). The two subspecies appear to be very closely related but distinct.

Description. - The carapace is elongate and wider posteriorly than anteriorly. The vetebrals are usually unkeeled, but young individuals may have a low, unserrated keel. The first pair of anterior marginals are distinctly smaller than the first vertebral. Marginal borders are not serrated. The ground color is light yellow-brown with darker spotting. This may be covered by a brown or black deposit in marshes, or faded white in old animals or in acidic environments.

The anterior lobe of the plastron is about 1.3 times the length of the abdominal scutes, and the interpectoral seam is equal to, or slightly longer than the length of the interhumeral seam. The intergular is pentagonal, parallel-sided and as wide, or wider than the gulars. The femorals are only moderately constricted at the base of the posterior lobe. The anal notch is acutely angled. The plastron is uniformly yellow but may be stained brown or black.

On the head the supralabial scale (between the postocular and the masseteric) is reduced; it may be absent or moderately large, and it does not completely separate the postocular

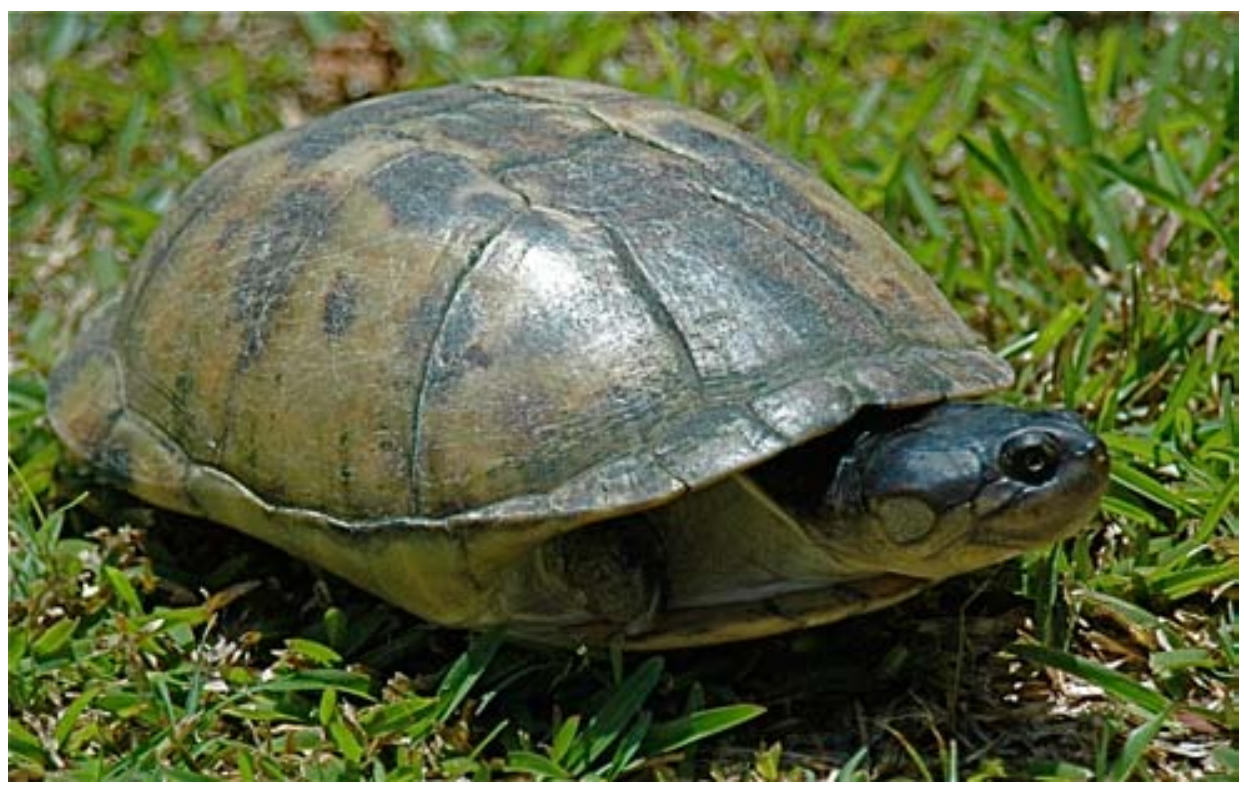

Figure 1. Pelusios castanoides intergularis: an adult from the Seychelles. Photo by Justin Gerlach. 


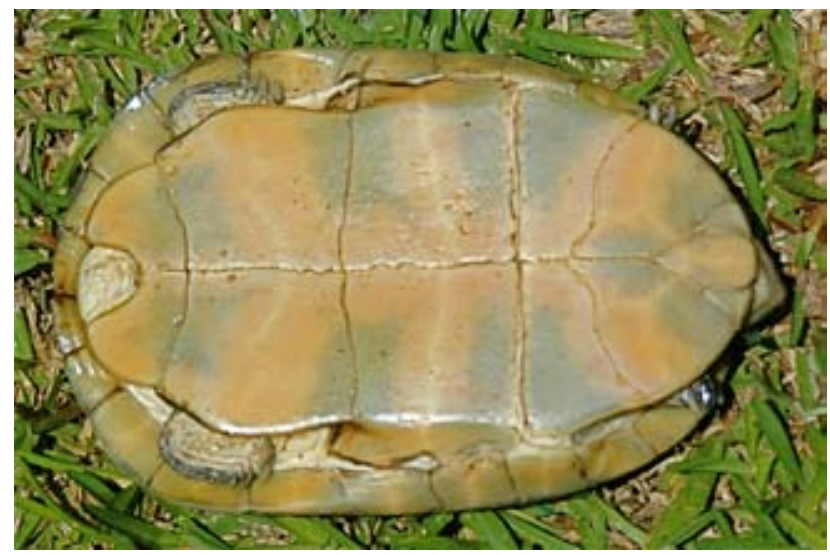

Figure 2. Pelusios castanoides intergularis: plastron of an adult from the Seychelles. Photo by Justin Gerlach.

masseteric scales. The dorsal surface of the head is yellow with dark brown to black vermiculations. The anterior forelimb is partially covered with 4-6 falciform (i.e., sickle-shaped) scales. The neural bones form a complete series anteriorly. The skull has reduced tuberculae basioccipitale compared to the nominate subspecies.

Females have a rounded anal notch. The notch in males is straight-sided, and male plastra may be slightly concave. Females are larger than males. The maximum size is 235 $\mathrm{mm}$ curved carapace length for females and $194 \mathrm{~mm}$ for males (normal range 124-212 mm).

Hatchlings have a black carapace with black marginals with yellow central patches; the plastron is black with yellow patches at the centers of the margins of each scute. The skin is gray, the dorsum of the head has black vermiculations, and the postocular, supralabial, and masseteric scales are yellow. There is also a yellow patch near the back of the inframandibular scale on the lower jaw.

No significant geographical variation has been detected within the Seychelles population and no mtDNA variation has

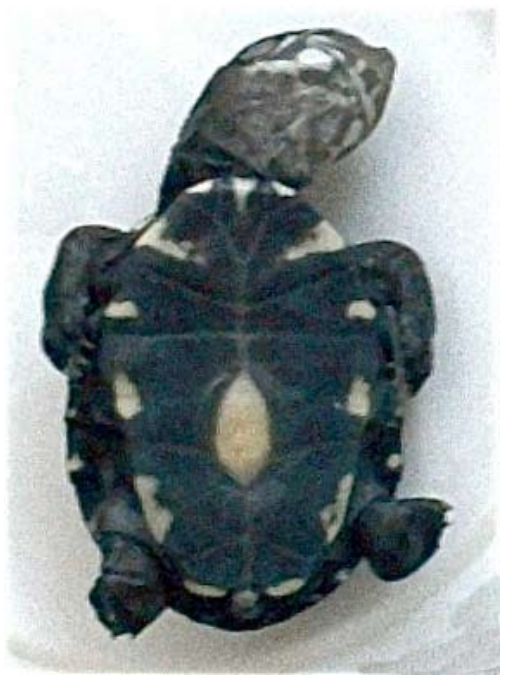

Figure 4. Pelusios castanoides intergularis: hatchling bred in captivity in the Seychelles. Photo by Justin Gerlach.

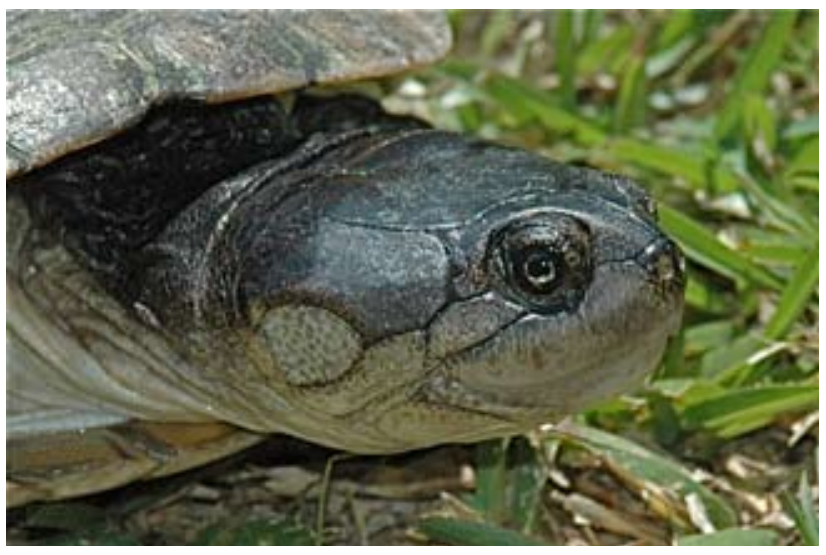

Figure 3. Pelusios castanoides intergularis: head of an adult from the Seychelles. Photo by Justin Gerlach.

been found (S. Rocha et al., unpubl. data). The Seychelles subspecies is distinguished from the nominate subspecies by the narrow intergular with S-shaped lateral margins.

Distribution. - Pelusios castanoides intergularis is endemic to the Seychelles (islands of Mahé, Cerf, Silhouette, Praslin, La Digue, and Fregate). There are nine distinct populations surviving (Gerlach 2008).

Habitat and Ecology. - Pelusios castanoides intergularis occurs in lowland rivers, with small numbers in some marshes; population densities were highest in rivers, reaching 133-150 turtles per ha (Gerlach and Canning 2001; Gerlach 2008).

Growth of captive bred individuals indicate that adult size may be reached after 2-3 yrs, but there are no data from wild animals on the age of sexual maturity or longevity. Mating may occur throughout the year, although the time of fertilization is not known. Nesting occurs during the wet season (December-March), and clutch size is 3-13, with elongate, soft-shelled eggs weighing 6.6-10.5 g each (Gerlach 2008)). Shallow nests are dug in sandy soil. Eggs incubated at $29-30^{\circ} \mathrm{C}$ have hatched after 51-52 days, but survival of hatchlings has been very low and it is thought that these have been premature and that natural incubation might be longer than 52 days. There is no information on sex determination.

Diet includes aquatic invertebrates, fish, amphibians and aquatic plants. Snails form a major part of the diet of breeding females. Most populations appear to be nocturnal, but in isolated areas diurnal activity has been observed; captive individuals are increasingly active during the day, suggesting that nocturnal behavior is at least partly a response to disturbance. Seychelles populations do not aestivate, although the nominate subspecies is reported to do so in Africa.

Population Status. - The total wild adult population of P. c. intergularis has been estimated to have declined from approximately 390 individuals in 1996-2000 to about 120 in 2000-05 (Gerlach 2008). Only four populations currently show evidence of reproduction (Gerlach 2008). 


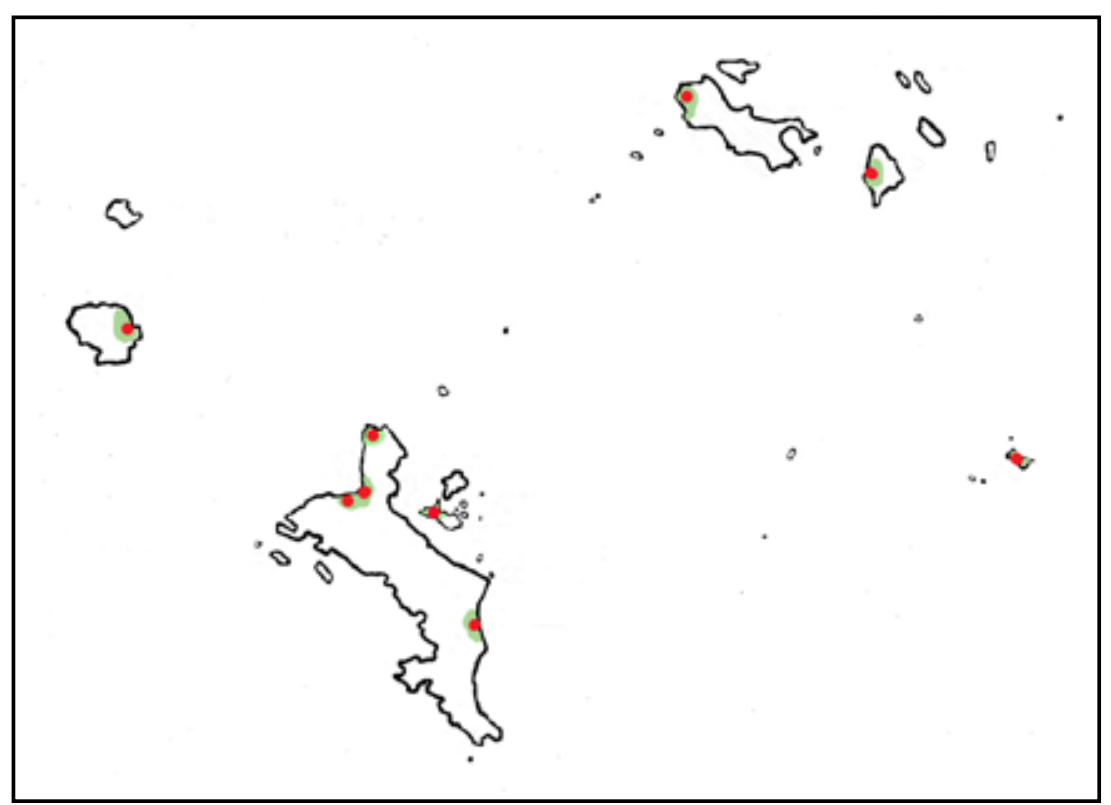

Figure 5. Distribution of Pelusios castanoides intergularis in the Seychelles islands, east of Africa in the Indian Ocean. Red points = museum and literature occurrence records based on recent and current author's data; green shading $=$ projected distribution based on author's data.

Threats to Survival. - Pelusios castanoides intergularis is threatened by drainage of wetlands, canalization reducing access to nesting areas, invasion of aquatic habitats by introduced plants (especially water hyacinth and water lettuce), and possibly predation of adults by dogs and of juveniles and eggs by cats and tenrecs. Historically, terrapins were captured for food and the curio trade, but these uses ceased $30-40$ years ago.

Conservation Measures Taken. - Protected under Seychelles law by the 1966 Wild Animals (Seychelles Pond Turtle) Protection Regulations (WAPR) that prohibit their capture. However, habitats are not protected. The declining status of the subspecies was documented by Gerlach and Canning (2001) who also proposed that it be listed on the IUCN Red List as Critically Endangered; this was soon accomplished (Gerlach 2003; IUCN 2007). The subspecies occurs in some protected areas in the Seychelles; it is present in the La Vev Reserve (La Digue), and a relict population is present in the Port Launay Ramsar Site (Mahé).

The Nature Protection Trust of Seychelles 'Seychelles Terrapin Conservation Project' includes monitoring, research, and captive breeding. The first captive breeding occurred in 2004, but to date only three individuals have been produced. Low breeding success has been due to hatching mortality of over $70 \%$, this is thought to be due to excessively high incubation temperatures. Small numbers of animals are kept in captivity in Europe, mostly as isolated individuals, with only one or two potential breeding pairs.

Conservation Measures Proposed. - The Seychelles Terrapin Action Plan (Gerlach 2002) proposed site protection and reintroductions for this subspecies. Reintroduction could potentially result in the establishment of at least three more secure populations totalling $650-850$ individuals. As a matter of urgency, all areas occupied by P.c.intergularis need to receive legal protection. Effective protection is needed to prevent any further habitat loss. Sites occupied by the subspecies should be restored to allow breeding and recruitment. Reintroductions are needed to secure these sites.

On-going captive breeding needs to be expanded to provide more individuals for reintroductions. It is important for research into captive breeding to be continued to determine optimal keeping, rearing, and reintroduction methods.

Captive Husbandry. - The only assurance colony for P.c.intergularis is maintained by the Nature Protection Trust of Seychelles (Gerlach 2003). These terrapins are largely aquatic and need large ponds with access to land areas, including sandy nesting sites. They are omnivorous, with a high demand for animal protein and calcium in the breeding season. Commercial terrapin food is suitable. Further research on incubation conditions is needed.

Current Research. - Research is currently being undertaken on ecology, distribution, population size, and population genetics. A high priority for future research is reproductive biology.

Acknowledgments. - Research on this species has been supported by the British Chelonia Group.

\section{LITERATURE CITED}

Bour, R. 1983. Trois populations endémiques du genre Pelusios (Reptilia,Chelonii,Pelomedusidae) aux îles Seychelles; relations avec les espèces africaines et malgaches. Bulletin du Muséum Nationale d'Histoire Naturelle, Paris (4)5A:343-382.

DumérIL, A.M.C. And Bibron, G., 1835. Erpétologie Générale ou Histoire Naturelle Complete des Reptiles, Vol. 2. Librairie 
Encyclopédique de Roret, Paris.

Gerlach, J. 2002. Seychelles Terrapin Action Plan. Phelsuma 10B:1-16.

GERLACH, J.2003 Five years of Chelonia conservation by the Nature Protection Trust of Seychelles. Testudo 5:30-41.

Gerlach, J. 2003. Pelusios castanoides ssp. intergularis. In: IUCN 2003.2003 IUCN Red List of Threatened Species. www. iucnredlist.org.

GerLach, J. 2008. Fragmentation and demography as causes of population decline in Seychelles terrapins. Chelonian Conservation and Biology 7(1):77-86.

Gerlach, J. AND CANNING, K.L. 2001. Range contractions in the Critically Endangered Seychelles terrapins (Pelusios spp.). Oryx 35:313-320.
IUCN. 2007. 2007 IUCN Red List of Threatened Species. http:// www.iucnredlist.org.

\section{Citation Format for this Account:}

Gerlach, J. 2008. Pelusios castanoides intergularis Bour 1983 - Seychelles yellow-bellied mud turtle, Seychelles chestnutbellied terrapin. In: Rhodin, A.G.J., Pritchard, P.C.H., van Dijk, P.P., Saumure, R.A., Buhlmann, K.A., and Iverson, J.B. (Eds.). Conservation Biology of Freshwater Turtles and Tortoises: A Compilation Project of the IUCN/SSC Tortoise and Freshwater Turtle Specialist Group. Chelonian Research Monographs No. 5, pp. 010.1-010.4, doi:10.3854/crm.5.010.intergularis.v1.2008, http://www.iucn-tftsg.org/cbftt/. 